\title{
PRESENCIA DE LA RIOJA JACOBEA EN LA LITERATURA FRANCESA*
}

\author{
IGNACIO IÑARREA LAS HERAS \\ Universidad de La Rioja \\ ignacio.inarrea@dfm.unirioja.es
}

\section{RESUMEN}

En este artículo se pretende ofrecer una visión muy amplia de la presencia que tiene La Rioja en la literatura francesa, como parte integrante del Camino de Santiago. Se aborda una cantidad notable de géneros (épica, poesía lírica, narración, drama, relatos de viajes y de peregrinación, canciones de peregrinos), repartidos a lo largo de un periodo muy largo, comprendido entre los siglos XII y XVIII. Las alusiones a La Rioja en los textos estudiados son realmente frecuentes, aunque no muy extensas. Por un lado, esto constituye una demostración de la importancia de esta región dentro de la ruta jacobea. Pero, por otro lado, confirma su condición de etapa, de elemento que forma parte de un universo cultural de gran dimensión, con las limitaciones que esta situación implica.

Palabras Clave: La Rioja: Camino de Santiago: Literatura francesa.

\section{ABSTRACT}

This article attempts to offer a panorama of the presence of La Rioja in French literature as a relevant step in the pilgrimage to Santiago. A range of genres are taken

* El presente trabajo forma parte de los resultados de un proyecto de investigación que ha contado con una ayuda económica procedente del Gobierno de La Rioja. I Plan Riojano de 1+D+i. Convocatoria de 2002. Proyecto ANGI 2002/01. 
into consideration (the epic, lyrical poetry, narrative, drama, travel and pilgrimage writings, pilgrims" songs), genres which span between the twelfth and the eighteenth centuries. Allusions to La Rioja in the corpus are very frequent, but not very long. This fact shows, on the one hand, the importance of this region in the pilgrimage to Santiago, but, on the other hand, it confirms its status as stage or phase, as an element which forms part of a cultural universe of much larger dimensions, with the limitations that this situation involves.

KeY wORDS: La Rioja, pilgrimage to Santiago, French literature.

Como es bien sabido, la historia de la peregrinación a Compostela concede a La Rioja un lugar de innegable importancia, justificada por varios motivos. En primer lugar, hay que mencionar su situación dentro del entramado de las rutas transitadas por los viajeros que desean visitar la tumba del apóstol. Atravesada por el Camino Francés, fue siempre zona de paso obligado para quienes entraban es España por Roncesvalles'. Aquí es importante tener en cuenta el gran impulso que los reyes de Navarra dieron en los siglos $\mathrm{X}$ y XI a la localidad de Nájera. Hicieron de ella su segunda residencia; Sancho III el Mayor acuñó allí la primera moneda cristiana de la Reconquista y modificó el trazado del Camino de Santiago, haciendo que pasara por La Rioja y, por lo tanto, también por Nájera, cuando anteriormente atravesaba el País Vasco; el hijo de Sancho el Mayor, García IV el de Nájera, fundó aquí el monasterio de Santa María la Real en 1052, así como una alberguería para peregrinos. Tras la incorporación de La Rioja a Castilla en 1076, Alfonso VI se ocupó de mejorar el estado de la Ruta Jacobea en estos territorios, y confirmó el fuero de Nájera, concedido por Sancho III $^{2}$. Además, gran cantidad de peregrinos procedentes de la Rioja Baja y de la Navarra ribereñas del Ebro, de Aragón, del Levante, de Cataluña, del sureste de Francia o de Italia se incorporaban en Logroño a este Camino Francés, no sin antes haber pasado por otras localidades riojanas como Alfaro, Rincón de Soto, Calahorra o Alcanadre, enclavadas en el llamado Camino del Ebro ${ }^{3}$. En segundo lugar, está la figura de Domingo de la Calzada (?-1109). Este santo ermitaño consagró su vida a mejorar las condiciones en que los peregrinos tenían que hacer su viaje al pasar por La Rioja, arreglando caminos, construyendo puentes y fundando en la población que luego llevaría su nombre una hospedería y la iglesia de San Salvador y Santa María ${ }^{4}$. Después de muerto, su fama no hizo sino aumentar, ya que se le atribuyeron milagros en los que prestaba ayuda a los peregrinos jacobeos ${ }^{5}$. Además, su culto llegó a alcanzar dimensión internacional, merced a los peregrinos extranjeros que regresaban a sus países. La compilación en lengua latina conocida como Liber Sancti Jacobi (siglo XII) no deja de hacer alusión a este santo en su libro V, lo cual confirma el gran alcance de su fama:

' Vid. Vázquez de Parga, Lacarra y Uría Ríu (1949, vol. 2: 144-169).

2 Vid., en relación con todas estas iniciativas de reyes de Navarra y de Castilla, Vázquez de Parga, Lacarra y Uría Ríu (1949, vol. 2: 155-156) y Passini (1984: 73).

${ }^{3}$ Vid. Vázquez de Parga, Lacarra y Uría Ríu (1949, vol. 2: 35-36) y Tobías Tobías, Ochoa Alfaro y Ochoa Moneva (1999: 27-61).

4 Vid. Vázquez de Parga, Lacarra y Uría Ríu (1949, vol. 2: 162-163).

5 Vid. Vázquez de Parga, Lacarra y Uría Ríu (1949, vol. 2: 164-167).

6 Vid. Vázquez de Parga, Lacarra y Uría Ríu (1949, vol. 1: 490). 
«Después se ha de visitar en España el cuerpo de Santo Domingo, confesor, quien hizo la calzada entre Nájera y Redecilla del Camino en donde descansa» (Anónimo, 1951: 549). Por último, no hay que dejar de hablar del prestigioso y muy difundido milagro del gallo y la gallina, acontecido, según cuenta la leyenda, en la localidad riojana de Santo Domingo de la Calzada, y del que más adelante se hablará con mayor detalle.

Un hecho que viene confirmar el notable valor y el prestigio (de alcance incluso internacional) de La Rioja como parte integrante del universo jacobeo es su presencia en numerosas obras literarias y musicales francesas y francófonas, pertenecientes a géneros igualmente variados: la épica y la lírica medievales, la narrativa, el drama, los relatos de viajes y de peregrinación y las canciones de peregrinos. Todas ellas están repartidas a lo largo de un periodo muy amplio, que se remonta al siglo XII y llega hasta finales del XVIII. En el presente trabajo se va presentar una visión lo más amplia posible (aunque no exenta de minuciosidad) de las alusiones que a La Rioja se hace en tales creaciones.

Primeramente, el género del cantar de gesta ofrece un conjunto de obras en las que la ruta jacobea tiene un valor narrativo primordial, siempre en relación, de una manera o de otra, con la figura heroica de Carlomagno. Se trata de las siguientes obras: la Chanson d'Agolant (finales del siglo XII o comienzos del XIII), Anseïs de Cartage (comienzos del siglo XIII), Gui de Bourgogne (también de comienzos del siglo XIII) L'Entrée d'Espagne (primera mitad del siglo XIV) y La Prise de Pampelune (hacia 1350). La base literaria común a todas ellas es el mencionado Liber Sancti Jacobi y, más concretamente, su libro IV. Contiene éste una historia legendaria sobre Carlomagno y Roldán, relatada y supuestamente escrita por el arzobispo Turpín. Se titula Historia Karoli Magni et Rotholandi o Historia Turpini y en ella se cuentan las invasiones de España y las batallas que Carlomagno debió llevar a cabo por indicación de Santiago, con el objeto de liberar el sepulcro de este apóstol ${ }^{7}$. Esto explica, sin duda, que en las cinco obras aparezca constantemente el personaje del emperador francés (siempre bien secundado por sus doce pares, entre los cuales destaca sobremanera su sobrino Roldán) como el gran guerrero al servicio del apóstol Santiago. La misión que se le ha confiado es la recuperación de las tierras españolas de manos de los sarracenos, restaurar el culto al santo y devolver al camino de Compostela su importante función como vía de peregrinación. En este sentido, es importante señalar que una característica común a las obras épicas francesas en las que se habla de España y del Camino de Santiago es la presentación de este país completamente dominado por los musulmanes, siendo su liberación posible gracias únicamente a la intervención militar procedente del país vecino. Como señala Elena Real Ramos:

Todos los poemas épicos coinciden en presentar las ciudades del camino, incluida la misma Compostela, como poblaciones sarracenas. La epopeya gala considera invariablemente [...] a los franceses como los únicos héroes cristianos de la Reconquista de España. Los hispano-cristianos desaparecen, pues, de los cantares de gesta franceses, que consideran invariablemente a los sarracenos como los únicos habitantes de nuestra Península. Sólo ellos viven en España, unidos por una misma religión, la de Mahoma, y por un mismo anhelo, el de atacar a los franceses, bien para ocupar el país vecino, bien para defender a España de los reiterados ataques francos. De modo que no existe ninguna diferencia para los poetas épicos entre Córdoba, por ejemplo, y León, Burgos o Santiago de Compostela (1991: 24-25).

7 Vid. Bédier (1966, vol. 3: 39-152) y Vázquez de Parga, Lacarra y Uría Ríu (1949, vol. 1: 499-513). 
Entre dichos cantares de gesta, son dos los que merecen ser tenidos en cuenta, por hacer referencia explícita suficientemente extensa a localidades riojanas situadas en la ruta jacobea. L'Entrée d'Espagne cuenta el comienzo de la campaña de Carlomagno en España. Después de unos 16.000 versos, el autor termina su obra dejando al emperador a las puertas de Pamplona, que continúa resistiendo a las fuerzas cristianas. Nájera aparece situada entre los Pirineos y Pamplona, justo después de Roncesvalles. El poeta cuenta la defensa de Nájera por Ferragut, la muerte de éste a manos de Roldán ${ }^{8}$ y la ocupación definitiva de la ciudad. Se puede ver, por ejemplo, cómo Marsilio, rey sarraceno de España, ante la inminencia de la llegada de Carlomagno a la Península, encarga a Ferragut que acuda a Nájera para desde allí intentar frenar el avance francés:

Li rois Marsille d'Aragoneise gient

En seul .VIII. jors a feit asenblement

De . $X^{M}$. homes, sin fist delivrement

A son neveu, Feragu d'Orient.

«Niés», dist li rois, «menez cist garniment

«A la citez qu'eu vos don et present,

«Ce est Laçarain [Nájera], que fu de ton parent.

"Le rois de France i vient certeinement;

«Contenez vos illoc si sajement

«E dou pasajes feites manteniment,

«Q'il non poissent passer legeirement.»

[...]

Por le comant Marsille l'aumanssor

Cevaucerent Feragu et cellor;

De Laçarain ferent garnir la tor.

(Anónimo, 1913, vol. 1: 24-25, vv. 595-617)

La Prise de Pampelune, compuesta por el italiano Nicolás de Verona, es una continuación de L'Entrée d'Espagne. Se asiste en ella a la caída final de Pamplona y a las siguientes conquistas de Carlomagno, a lo largo de la ruta jacobea hasta la ciudad de Astorga. Las tropas francesas pasarán necesariamente por La Rioja y llevarán a cabo la conquista de la ciudad de Logroño, de forma totalmente pacífica, ya que Altumajour, señor de Estella y de Logroño, se la entrega. Después de haber tomado esta localidad navarra, los franceses

S'en istrent de la ville sens nule destourbance

Et tant esploiterent ou la Jesu sperançe

Che au Groing [Logroño] furent venus, mes par mout grand sciançe

Se fist Altumajour venir en sa presançe

Li gregnour de la terre, e pues sens arestançe

Entrerent nous Franzois dedens en comunançe,

Che ja ne i fu meslee ne nule destorbançe,

Pour ce che le castel estoit a oubedience

De Altumajour, où tous avoient fiançe.

(Nicolás de Verona, 1864: 67, vv. 2417-2424)

${ }^{8}$ En relación con el personaje de Ferragut y su lucha con Roldán, vid. Gil del Río (1984). 
Gui de Bourgogne ${ }^{9}$ presenta en su comienzo a Carlomagno y a sus barones en España, donde han pasado veintisiete años, conquistando gran cantidad de ciudades y castillos. El emperador se dirige a sus hombres para proponerles ir a apoderarse de Córdoba, la única población que aún no han tomado. Ogiero el Danés se opone a tal idea y le reprocha a Carlomagno su pasividad en todas las empresas guerreras realizadas hasta el momento. Son sus caballeros, y no él, quienes las han llevado a cabo. Carlomagno le contesta diciéndole que sus reproches son injustos, pues él también ha luchado y se ha sacrificado como el que más. Empieza entonces a hacer una relación de los lugares conquistados por él, entre los cuales menciona Logroño:

«Primes conquis Bordele par ma chevalerie,

«Et si fis à Pamers estorer une vile;

«Pris le Groing et l'Estoile et Quarion ausinques.

«De toutes ices terres ai je la seignorie;

"Qui s'i reclameroit de la moie partie,

«Enorez i seroit, là ne faudroit il mie.»

(Anónimo, 1966: 3, vv. 68-73)

Otinel, creación épica compuesta probablemente en el siglo XIV, contiene también una alusión a Nájera. Esta obra está vinculada por su temática con las aventuras de Carlomagno en España, si bien se desarrolla en Italia ${ }^{10}$. Relata la expedición del monarca francés en Lombardía contra Garsile (Marsilio). El personaje principal de la historia, Ilamado Otinel, se muestra inicialmente como enemigo de los cristianos. Es el mensajero enviado a París por Garsile con el objeto de instar a Carlomagno a reconocerlo como su soberano y a convertirse al islam. Otinel se identifica ante el emperador tal y como sigue:

Lors parle Karle, le rois de Saint Denis:

«Sarrasins frere, par la loi dont tu vis,

«De quel linage es tu an ton païs?

«Commant as nom [par ta lei] quar me dis.

- Sire, dit-il, Otes li Sarrarins.

«[Fiz sui al rei] Galien au fier vis;

«Moie est la Marche et trestot le païs,

«Et Benoas, qui tant est de haut pris,

«Une contrée qui moult est postéis

«De totes pars d'estraingles Sarrasins;

«Et aumacours et tous les Barbaris,

«Tous me redotent, par foi le vos plevis.

«Li rois Garsile est mes germains cousins,

«Mes oncles fu Fernagu [Ferragut] li gentis,

«[Icil de Nazze (Nájera)], que Rollans m'a ocis.

«Demain en iert .i. fier chaple bastis.»

(Anónimo, 1966: 9, vv. 230-245)

${ }^{9}$ Sobre esta obra, vid. Bédier (1966, vol. 3: 137-140).

10 «Quoiqu'il se dénoue en Italie, le poëme d'Otinel se rattache à l'histoire légendaire de la conquête de l'Espagne par Charlemagne, et s'intercale, comme une sorte de parenthèse, dans le récit de cette grande expédition. L'auteur suppose, en effet, qu'après la prise de Pampelune Charlemagne est rentré en France avec ses pairs, et qu’il est sur le point de retourner en Espagne pour y combattre.» (Anónimo, 1966: V-VI). 
En 1478, tiene lugar en Ginebra la publicación de la primera edición de L'Histoire de Charlemagne (parfois dite Roman de Fierabras), escrita par Jehan Bagnyon (1412-?). Se trata de una obra narrativa en prosa, compuesta en alabanza del duque Pedro II de Saboya, a quien se quiso identificar con Carlomagno. Por sus contenidos tiene una estrecha vinculación con el género épico. Se compone de tres grandes capítulos o libros, de los cuales el último relata la campaña de reconquista de España por el emperador. En realidad, es una traducción de la Historia Turpini, realizada fundamentalmente (aunque no exclusivamente) según la versión incluida en el Speculum Historiale (siglo XIII) de Vincent de Beauvais'". Al igual que L'Entrée d'Espagne, esta obra contiene el relato de los combates contra el gigante Ferragut, la muerte de éste y la toma de Nájera.

Aprés que Aygolant fut occis et Furré et pluseurs roys sarrazins, comme devant est dit, les nouvelles vindrent a l'admiral de Babillonne, lequel avait ung jayant moult terrible, qui estoit de la generacion de Golyas, et le fist accompaignier de .XX. ${ }^{\mathrm{m}}$ Turcqs moult fors et puissans et l'envoya pour batailler contre Charles l'empereur, car sa puissance estoit redoubté par tout le monde. Et s'en vint le dit Ferragus jusques en la cité de Nageres [Nájera] prés de Saint Jacques, entre crestienté et les païs sarrazinois, et manda au roy Charles qu'il vinst a luy pour batailler. [...] Tantost que Charles sceut la venue de celluy jayant, il alla aluy et fut en sa garde prest de Nageres. (Jehan Bagnyon, 1992: 193) ${ }^{12}$

En lo que concierne al ámbito lírico cortés, hay que señalar que los poetas occitanos conceden también un cierto lugar en sus producciones a la peregrinación a Compostela ${ }^{13}$, aunque no es realmente muy importante. En realidad, lo único que hacen es incluir algunas alusiones a este universo en composiciones cuya temática poco o nada tiene que ver con él.

Paulet de Marsella escribió en 1268 un sirventés titulado Ab marrimen et ab mala sabenza. Estaba dirigido a Alfonso X de Castilla, en apoyo de su hermano Enrique. Le pide que lo libere de su encierro en Montecasino, tras la batalla de Tagliacozzo (23 de agosto de 1268$)^{14}$ :

Tug l'Espanhol del Gronh tro Compostelha

Devon planher la preizo que ges belha

Non fo ni es d'En Enric de Castelha,

El reis N'Anfos, que tant gen se capdelha

Ab sen antic,

Deu demandar tost son fraire N'Enric.

(Lévy, 1882: 279-280, vv. 13-18. Bibliothèque nationale de France/Gallica)

11 «Le troisième livre représente une traduction fidèle du Pseudo-Turpin, traduction qui est faite pour la grande partie d'après les chapitres 6 à 25 du livre XXIV du Speculum Historiale. Mais il n'y a pas de doute que Bagnyon s'est aussi servi d'une version indépendante du Pseudo-Turpin, qui dut constituer une des croniques auxquelles il fait allusion dans le 'Prologue', car il y a bien des passages où il dévie de l'ouvrage de Vincent de Beauvais.» (Jehan Bagnyon, 1992: XXIII), Vid. también Mandach (1987: 148).

12 Vid. también Jehan Bagnyon (1995; 598).

13 Vid. al respecto Heur (1967).

14 Vid. Heur (1967: 260-261). 
Compostela y Logroño aparecen aquí como las ciudades que vienen a mostrar, por su situación límite (una en Galicia, la otra en la frontera con el reino de Navarra), toda la dimensión del reino de Castilla de un extremo a otro. Esto permite hacerse una idea del gran número de personas (españoles: Tug l'Espanhol) que lamentan la situación de Enrique de Castilla. Esta impresión de grandeza queda acentuada, sin duda, por la referencia clara, aunque no demasiado explícita, al larguísimo tramo de la ruta jacobea comprendido entre ambas localidades.

A finales del siglo XVI, aparece la Histoire de la vie, prédication, martyre, translation et miracles de sainct laques le Majeur publicada por primera vez en 1595 en Orleáns y reeditada después en 1603 en Ruán. Se trata de una compilación en la que se recogen la vida y leyenda de Santiago, sus milagros y algunos textos litúrgicos en latín. La colección de milagros a la que da cabida contiene las dos versiones del conocido relato del ahorcado: la que se sitúa en Toulouse y la de Santo Domingo de la Calzada $^{15}$. La primera de ellas es seguramente la más antigua, según los testimonios escritos conservados, tanto en latín como en francés ${ }^{16}$. Su base narrativa viene a ser la siguiente: dos peregrinos alemanes, padre hijo, que tienen la intención de ir a Santiago, se detienen en la ciudad francesa de Toulouse para pasar la noche y se alojan en un albergue. Llevan consigo mucho dinero, lo cual excita la codicia del posadero, que les hace beber hasta emborracharlos. Una vez que se han quedado dormidos, esconde una copa de plata en uno de sus zurrones, con el propósito de acusarles de robo, hacer que los detengan y quedarse con sus bienes. Al día siguiente, cuando los peregrinos han reemprendido el camino, el posadero, acompañado por unos guardias, se lanza en su persecución. Les acusa, registra los zurrones y encuentra la copa. Los peregrinos son llevados ante el juez, que decide que uno de ellos quede libre y el otro sea ahorcado. Es el hijo quien se ofrece voluntariamente a ser condenado, por lo que el padre tendrá que seguir solo hasta Compostela. Al cabo de treinta y seis días el padre, ya de regreso, vuelve a pasar por el albergue para ver el cuerpo de su hijo, que aún está colgado. Descubre que éste no ha muerto, ya que el apóstol Santiago lo ha sostenido con sus propias manos. Sale corriendo en dirección a la ciudad, para informar sobre este prodigio. Se comprueba que dice la verdad y que se ha cometido una injusticia por culpa del posadero. Se hace bajar al joven de la horca y, después de ser juzgado, se condena a la misma pena al culpable de haber lanzado las falsas acusaciones. El relato termina con el consejo de no engañar a las gentes de bien y de dar buena acogida a los peregrinos.

Este relato milagroso se recoge en el libro II del Liber Sancti Jacobi donde aparece en quinto lugar. Forma parte igualmente del Dialogus Miraculorum (1220-1235) de Cesáreo de Heisterbach. Conoció una gran difusión, gracias sobre todo al mencionado Speculum historiale de Vincent de Beauvais (parte integrante del Speculum majus, escrito por este autor entre 1240 y 1260) y a la Legenda aurea (hacia 1260) de Jacopus de Vo-

15 Vid. Anónimo (1603: ff. $65 \mathrm{r}^{9}-67 \mathrm{v}^{\mathrm{o}}$ ).

16 Vid. Vázquez de Parga, Lacarra y Uría Ríu (1949, vol. 1: 576-577) y Henrard (1998: 331-332). 
ragine, obras en las que también se incluye ${ }^{17}$. De hecho, el Speculum historiale es la fuente de la que se ha nutrido la Histoire de la vie, prédication, martyre, translation et miracles de sainct Iaques le Majeur ${ }^{18}$.

En cuanto a la segunda versión, la historia que cuenta presenta notables diferencias con respecto a la anterior ${ }^{19}$. Tres peregrinos alemanes, padre madre e hijo, se dirigían a Compostela. Se detuvieron a pasar la noche en un albergue de Santo Domingo de la Calzada. Una sirvienta se prendó del muchacho, pero éste no le hizo caso. La joven, molesta por este rechazo, se vengó de él introduciendo en su escarcela, mientras dormía, una taza de plata del posadero. A la mañana siguiente, la familia continuó su viaje. Poco después, la criada denunció el robo de la taza y acusó a los peregrinos. Éstos fueron detenidos en el camino. Se registraron sus escarcelas y encontraron la taza en la del muchacho. Fueron llevados a la ciudad y el juez condenó al joven a morir ahorcado. Sus padres continuaron la peregrinación y al regreso fueron a la horca a ver a su hijo y se lo encontraron vivo. El muchacho les dijo que el apóstol Santiago le había sujetado y alimentado durante todo este tiempo. Los padres fueron a la ciudad a ver al juez y le contaron el hecho milagroso. El juez no les creyó y les dijo, ante su insistencia, que tan pronto creería que el pollo que se disponía a comer cantaría como que el peregrino estaba vivo. En ese momento, el pollo recobró la vida, cantó y echó a volar. Ante tal prodigio, el juez y toda la gente de la ciudad fueron donde estaba colgado el joven y comprobaron que, efectivamente, no había muerto. Éste fue descolgado y llevado a la iglesia para dar gracias a Dios. En la Histoire de la vie, prédication, martyre, translation et miracles de sainct Iaques le Majeur, el relato termina como sigue:

Et retournerent le pere \& la mere auec leur fils rendre graces à Dieu, en l'Eglise saint Iacques par les merites duquel cest excellent miracle estoit aduenu. Aucuns disent que ce pelerin, apres auoir rendu graces à Dieu en l'Eglise, rendit l'esprit à Dieu, \& fut mis en sepulture en ladite Eglise saint Dominique. Et pour punir l'offence commise par cette mauuaise garse de chambriere, elle fut condamnee à estre bruslee viue. En quoy est grandement admirable \& louable l'equitable iugement de Dieu, qui conserue $\&$ deliure les innocens, $\&$ punist griéuement les calomniateurs, \& faux accusateurs. (Anónimo, 1603: f. 67 vo )

El campo dramático también ha encontrado una fuente de inspiración en la peregrinación a Compostela. Ya desde la Edad Media existían en Francia numerosas localidades (de mayor o menor importancia) en las que se habían fundado cofradías de Santiago. Éstas organizaban con regularidad, al menos desde el siglo Xv, representaciones de misterios sobre la leyenda y los milagros del Apóstol, que tenían lugar sobre todo el día de la fiesta del Apóstol, el 25 de julio. Como señala José Filgueira Valverde,

${ }^{17}$ El título original en latín de este relato es De peregrino suspenso quem beatus apostolus triginta sex diebus in patibulo pendentem a morte obseruauit (Del peregrino colgado a quien el santo Apóstol salvó de la muerte, aunque estuvo pendiente en el patíbulo treinta y seis días). Vid. Anónimo (1944: 259-260 y 267-268). Anónimo (1951: 336 y 347-348), Santiago de la Vorágine (1982, vol. 1: 401-402) y Vincent de Beauvais (1990: 1371-1372). Vid., asimismo, Vázquez de Parga, Lacarra y uría Ríu (1949, vol. 1: 577).

18 Vid. Anónimo (1603: f. 59 ri).

${ }^{19}$ Vid., en relación con esta segunda versión, Gil del Río (1999: 231-265). 
Les épisodes de la Translation trouvèrent aussi place dans le théâtre religieux, à l'instigation des églises dont saint Jacques était le patron ou des confréries qui lui étaient vouées, installées et animées pour une grande part grâce à ceux qui avaient fait le voyage de Compostelle et gardaient avec la ville des liens de fratrenité. $(1985: 185)^{20}$

De tales producciones dramáticas solamente existen en la actualidad dos testimonios conocidos. Por desgracia, no se conserva el texto íntegro de ninguno de ellos, sino solamente una parte, que en ambos casos es la inicial. Sin embargo, estos fragmentos son lo bastante extensos como para poder comprobar con seguridad que, a pesar de las diferencias que hay entre ellos, dan comienzo a la misma historia, que no es otra que la del peregrino ahorcado, que se acaba de mencionar. Las dos obras presentan a la familia de tres peregrinos (los padres y el hijo), así como a la joven que se enamora del muchacho y que por despecho urde la falsa acusación, lo cual las aproxima claramente (al menos en principio) a la versión «riojana» del milagro.

Por una parte, se encuentra Le Miracle des trois pèlerins de Saint-Jacques, obra encontrada por Gilbert Ouy en los años $60 \mathrm{del}$ pasado siglo xx y editada por él mismo en $1984^{21}$. El texto se conserva en un manuscrito del siglo Xv. Sin embargo, se trata seguramente de una copia realizada a partir de un ejemplar más antiguo, ya que la lengua en que fue escrita corresponde por sus rasgos a una época anterior, probablemente al final del siglo XIII ${ }^{22}$. El aspecto que más llama la atención en esta creación es su episodio inicial, ajeno por completo a la historia milagrosa jacobea ${ }^{23}$. Cuando los tres peregrinos ya se han puesto en marcha, se encuentran con un campesino al que piden que les indique el camino que han de seguir hasta Compostela. Este hombre, tan bruto como estúpido, se burla de ellos de dos maneras. Primero finge no oírles bien y les contesta de forma grosera. Luego les indica la dirección opuesta a la que deben seguir. Posteriormente, aparece el hijo de este campesino, que le trae con retraso la comida. Ante el enfado de su padre, se excusa diciendo que si no ha llegado antes es porque han recibido en casa una carta del Papa de Roma. El campesino se cree semejante excusa sin poner objeción alguna. La importancia de este pequeño episodio cómico para el presente trabajo reside, en buena medida, en que permite ver que la historia no se sitúa en España (en Santo Domingo de la Calzada), sino en Francia, concretamente en el territorio de la Champaña. Los nombres de las localidades mencionadas por el campesino, al dar sus falsas orientaciones a los peregrinos, permiten asegurarlo (Villemorien, Pont-sur-Seine, SommeBionne, Lhuys, Gandelu) $)^{24}$ :

Je te enseigneray le païs

Par ou a Saint Jaquez yras;

De vint lieuës t'adreseras:

Va t'an droit a Ville Merien,

\footnotetext{
${ }^{20}$ Vid. también al respecto Manier (1890: XVIII-XIX) y Vázquez de Parga, Lacarra y Uría Ríu (1949, vol.

${ }^{21}$ Vid. Ouy (1984: 93-95) y Henrard (1998: 333).

22 Vid. Ouy (1984: 105-108).

${ }^{23}$ Vid. Ouy (1984: 102).

24 Vid. Ouy (1984: 105 y 116, vv. 66-69).
} 1: 250 ). 
A Pons sur Seine, a Somme Brien,

A Provatins et danqu'a Lus,

Et puis par dessouz Gandelus.

(Ouy, 1984: 116, vv. 63-69)

Probablemente, se trata de una obra escrita por encargo para alguna cofradía de peregrinos de la zona ${ }^{25}$. El autor habría introducido aspectos o elementos locales para atraer el interés del público de la región ${ }^{26}$.

Le Miracle des trois pèlerins de Saint-Jacques se interrumpe justo antes de que se inicie el juicio del muchacho.

Por otra parte, está el Ludus sancti Jacobi, de finales del siglo xv, concretamente de 1495. A pesar de su título en latín, se trata de un texto en provenzal ${ }^{27}$. En él no aparece ningún marco o referencia geográfica que permita situar de modo concreto el desarrollo de la acción. Presenta una característica digna de atención, en relación con el presente trabajo. Se trata del prólogo, el cual aparece a continuación de una introducción cuya finalidad era de tipo publicitario, pues se recitaba en los días previos a la representación con el objeto de atraer la atención del publico ${ }^{28}$. En este prólogo se ofrece, a lo largo de casi cien versos, una larga explicación anticipada del contenido de la obra. Se alude, por ejemplo al mal comportamiento de la criada:

Et ella si vay esmaginar
Cousi ella poyria far
Que ella fossa vengada
Car el lavia refueso
Et del demon fonc tentea
Que ella degessa maniera trobar
Que en sa maleta degues butar
Una tassa dargent
Affin que el fos pendut en continent.
(Anónimo, 1858: 5, vv. 114-122)

Su función consiste en informar al espectador acerca del desarrollo dramático que va a presenciar, incluida la conclusión. Esto implica la total desaparición, para los asistentes a la representación, de todo margen para la incertidumbre, el suspense o la sorpresa en la acción. Este tipo de prólogo es corriente en el teatro medieval francés:

Cette œuvre [el Ludus sancti Jacobi] ne constitue pas une exception dans le répertoire médiéval, où le suspense n'est pas un véritable élément d'attrait: la plupart des prologues dévoilent l'action qui va se jouer et d'ailleurs, d'une manière générale, le spectateur prenait plaisir à voir ou à revoir des situations qu'il connaissait déjà. (Henrard, 1998: 330, n. 5)

Llama la atención el que no se incluya en este prólogo ninguna referencia al segundo milagro de la historia, el de la resurrección de las aves asadas en casa del juez. Sí se

\footnotetext{
25 Vid. Ouy (1984: 105).

26 Vid. Ouy (1984: 105).

27 Vid. al respecto Henrard (1998: 328-329 y 334-335).

28 Vid. Henrard (1998: 329-330).
} 
habla de la intervención del apóstol Santiago, quien, por indicación de Dios, salva de la muerte al joven peregrino sosteniéndolo en el cadalso (vid. Anónimo, 1858: 5, vv. 133136). A ella se vuelve a hacer alusión al final de esta parte de la obra, donde además se anticipa el severo castigo que sufrirá la criada:

Coma sant Jame amic de Dieu
Car aussi creso ben ieu
Par la requesta de Jesus Christ
Miracle al pellegrin fet
Que tor lo van gardar
Como dessus declararan
Et la serventa nonea Beatriz
Li fero son cur marit
Et si la feron cremar
Et la van butar
Car ella vo avio ganhat
(Anónimo, 1858: 6, vv. 153-163)

Como se ha dicho, tanto Le Miracle des trois pèlerins de Saint-Jacques como el $\mathrm{Lu}$ dus sancti Jacobi presentan en sus respectivas tramas elementos propios de la versión «riojana» del milagro del ahorcado. Por ello, teniendo en cuenta la innegable importancia del episodio del gallo y la gallina para el feliz desenlace de esta historia, junto con lo que se acaba de indicar acerca de la ausencia de suspense en la obra provenzal (y en muchas otras de su época), sorprende que no sea mencionado. A no ser que, precisamente, el autor de este drama no lo hubiera contemplado como parte de la leyenda. Es importante tener presente aquí la evolución que de los contenidos del milagro del ahorcado establece Henrard, desde la versión situada en Toulouse (más antigua) hasta la que transcurre en Santo Domingo de la Calzada:

Bientôt l'histoire connut des variantes. À une date ancienne mais indéterminée, la mésaventure des pèlerins fut contaminée par un motif littéraire répandu, celui de la jeune fille qui fait condamner un innocent. [...]

Au contact de ce thème, l'histoire des pèlerins se transforma donc et l'ignominieuse accusation frappant l'un des voyageurs trouva un nouveau mobile: ce n'est plus la cupidité de l'aubergiste qui conduit le malheureux à sa perte, mais la vengeance perfide d'une jeune femme repoussée, tantôt la servante du lieu d'étape, tantôt la fille des hôteliers.

Simultanément, les narrateurs apportèrent au récit d'autres modifications: la troupe d'Allemands se mua en une famille composée d'un père, d'une mère et d'un adolescent; originairement situé à Toulouse, l'événement fut déplacé et localisé en Espagne, à Santo Domingo de la Calzada. Bientôt, on ajouta aussi une péripétie qui apportait au miracle une touche supplémentaire de merveilleux. Quand les parents (ou le père seul) du jeune pendu vont annoncer au juge que leur fils vit toujours, le magistrat manifeste un profond scepticisme: il ne croira cette nouvelle inouïe que si la poule et le coq rôtis qu'il s'apprête à manger se remettent à chanter. Son incrédulité doit évidemment céder lorsque les animaux ressuscitent. (1998: 332-333)

Es posible que la historia utilizada para la composición del Ludus sancti Jacobi constituya una etapa intermedia dentro de la evolución que se acaba de mostrar. Se trataría de 
una versión distinta de las otras dos, en la cual todavía no llegó a incluirse el prodigio del gallo y de la gallina, aunque sí aparecería la familia de los tres peregrinos y la malvada muchacha. Aunque, por otra parte, también podría ser un híbrido formado a partir de los relatos de Toulouse y de Santo Domingo de la Calzada. Dadas las semejanzas existentes entre ambos, junto con la amplia difusión popular que alcanzaron en la Europa medieval, podrian haberse producido entre ellos confusiones, mezclas o intercambios de elementos narrativos. En cualquier caso, no se puede afirmar con total seguridad que este milagro pudiera incluirse al final del Ludus sancti Jacobi ${ }^{29}$. Aun así, el hecho de que este drama no se conserve en su totalidad permite dejar en tal aspecto un cierto margen a la incertidumbre.

Esta obra queda interrumpida cuando los tres peregrinos están cenando en la posada y la criada aún no ha intentado seducir al hijo.

Como se acaba de anticipar, la versión del milagro del ahorcado que se sitúa en Santo Domingo de la Calzada llegó a ser muy conocida en toda Europa desde la Edad Media. Esto fue debido sobre todo a que los peregrinos jacobeos extranjeros, en el trayecto de regreso desde España a sus tierras de origen, no dejaban de contarla como la historia más asombrosa que jamás habían oído ${ }^{30}$. Es posible que esta influencia de procedencia española (y, por lo tanto, riojana) esté en el origen de la creación de Le Miracle des trois pèlerins de Saint-Jacques, a pesar de su episodio inicial y de que, como ya se ha señalado, su desconocido autor situara el desarrollo de la historia en la región francesa de la Champaña. Gilbert Ouy, en su edición de esta obra, no habla en ningún momento de tal influencia española; sin embargo, se muestra claramente partidario de proponer el milagro del gallo y la gallina como posible culminación para el drama, basándose en las grandes semejanzas de contenido existentes entre él y una canción popular francesa que recoge esta leyenda $^{31}$. Con todo, al no haberse conservado el texto íntegro de Le Miracle des trois pèlerins de Saint-Jacques y no tener ninguna constancia de que incluya la resurrección de las aves asadas, resulta preferible no hacer al respecto afirmaciones demasiado terminantes.

En cuanto al Ludus sancti Jacobi, a la vista de todo lo que se acaba de indicar, la cautela ha de ser aún mucho mayor al valorar el posible alcance en esta obra de dicha influencia riojana.

En el terreno musical (por lo tanto, no estrictamente literario) $)^{32}$, es preciso hablar de las canciones populares de peregrinos franceses. Se trata de composiciones que fueron

29 A este respecto, y basándose en las indicaciones del prólogo del Ludus sancti Jacobi, Henrard propone una continuación y un desenlace para esta obra: «Par le résumé donné dans le prologue, nous savons comment se termine l'histoire: l'adolescent refuse les avances de la jeune femme, qui se venge en cachant une tasse d'argent dans la besace du voyageur. Celui-ci est poursuivi par la justice, arrêté, incarcéré et pendu. Mais le bon apôtre vient le soutenir et le sauve d'une mort certaine" (1998: 330-331).

30 Vid. Vázquez de Parga, Lacarra y Uría Ríu (1949, vol. 1: 579).

31 Vid. Ouy (1984: 99-101).

32 Es necesario precisar aquí que las creaciones pertenecientes al universo de la poesía lírica cortés (al cual se ha hecho alusión anteriomente) son composiciones que también fueron concebidas para ser cantadas (vid. $\mathrm{Ri}$ quer, 1992, vol. 1: 19, 30-31 y 70-71; Riquer y Riquer, 2002: XIV-XV). Por lo tanto, la música es en ellas un elemento constitutivo esencial. De todas formas, el serventés de Paulet de Marsella no ha sido incluido en esta parte del presente trabajo porque tiene una naturaleza muy diferente de la de las canciones de peregrinos. De hecho, el mundo jacobeo no es en él, ni mucho menos, un componente temático principal. 
surgiendo como resultado o consecuencia espontánea de la propia actividad de peregrinación hacia Compostela. Se puede considerar que son casi tan antiguas como la propia peregrinación jacobea desde Francia. Por desgracia, en la actualidad apenas existen manifestaciones concretas de cantos medievales franceses ${ }^{33}$. Esto se explica si se tiene en cuenta el carácter fundamentalmente oral de su creación y transmisión. Los testimonios escritos comienzan a aparecer en el siglo XVII. Aunque no hay dejar de mencionar el relato del peregrino italiano Bartolomeo Fontana, que cuenta cómo en el transcurso de su viaje a Compostela en 1539 , al llegar a Asturias, recordó los versos de un canto de romeros franceses dedicados a esta región ${ }^{34}$.

A partir del siglo XVII, se asiste sobre todo en Francia a la aparición de una intensa actividad de recopilación y edición de canciones e itinerarios de peregrinación. Aparecían recogidos en pequeños libros, prácticamente unos folletos, de elaboración rudimentaria y de precio asequible, que eran destinados a ser vendidos a los viajeros con destino a Compostela. Al mismo tiempo, también salieron a la luz estampas con la imagen del apóstol rodeada de plegarias y alguna de estas canciones. La ciudad de Troyes aparece en esta época como el centro de edición más importante de estas publicaciones ${ }^{35}$. Seguirán apareciendo a lo largo del siglo XVIII; pero en el XIX, con la decadencia de la peregrinación compostelana, irán cayendo progresivamente en desuso. A pesar de ello, aún se publicarán algunos de dichos folletos, concretamente en Carcasona ${ }^{36}$.

Existen fundamentalmente dos tipos de canciones en las que, de una u otra forma, se da cabida a La Rioja como parte integrante del universo jacobeo.

En primer lugar, se encuentran las llamadas canciones de itinerario o cantos-guía. Es el más numeroso y seguramente el más importante. El hecho de que se conserve de ellas un número mayor permite suponer que tuvieron en su momento un uso y una difusión muy considerables. Su función esencial era ofrecer a los peregrinos una serie de orientaciones e informaciones de considerable variedad, muy útiles para la realización de su viaje a Compostela:

${ }^{33}$ Abel Beaufrère y René Nelli son autores de las ediciones respectivas de dos variantes de una misma canción jacobea francesa. Se trata de un canto de itinerario en lengua de oc, al que bien se podría dar el título de Complainte des Pèlerins d'Aurillac. Ambos estudiosos coinciden en señalar que su antigüedad es considerable, pues sitúan su origen en el siglo XJV (Nelli en sus comienzos y Beaufrère en su segunda mitad o, incluso, a principios del XV). De todas maneras, según señala Beaufrère, esta complainte fue publicada por primera vez en 1864 en el Dictionnaire statistique du Cantal. Vid. Beaufrère (1978: 48 y 60) y Nelli (1980: 87-88).

$\$ 4$ Vid. Vázquez de Parga, Lacarra y Uría Ríu (1949, vol. 1: 537) y, sobre todo, Fucelli (1987). Bartolomeo Fontana escribió un relato de su viaje, al que dio el siguiente título: Itinerario o vero viaggio da Venetia a Roma... seguendo poi per ordine di Roma fino a Santo Jacopo in Galitia, Finibus Terre, la Barca, il Padrone et Santo Salvatore... Fue impreso en Venecia en 1550. La obra de Fucelli contiene una edición del relato de Bartolomeo Fontana, junto con un estudio del mismo y una descripción del itinerario seguido por este peregrino. El pasaje que dedica a los peregrinos franceses es el siguiente: «La mattina seguente, come l'alba apparse, mi levai e poco discosto trovai l'hospital de peregrini, al quale al foco mi asciugai e senza firmarmi punto, mi partei e pervenni sopra un fiumicello, il qual per gran pezza seguitai, e in fine lo lasciai, e per bellissimo paese andai che parea proprio il paradiso deliciano e chiamasi Asturia, sopra il quale i peregrini francesi, in una sua canzone, composta sopra il viaggio de Galitia, dicono alcuni versi, che in nostra lingua suonano: "O Asturia, bella Asturia, tu sei pur bella e sei pur dura"” (Fucelli, 1987: 112-113).

33 Vid. Daux (1899: 13).

36 Vid. Anónimo [1862] y Vázquez de Parga, Lacarra y Uría Ríu (1949, vol. 1: 538). 
- Ante todo, presentan habitualmente un recorrido completo desde el norte o el oeste de Francia hasta Santiago. Dan cabida a las etapas consideradas más importantes, o más dignas de mención, de este trayecto. Como se verá más adelante con mayor detalle, entre ellas casi siempre ${ }^{37}$ se encuentra Santo Domingo de la Calzada. En el libro de la cofradía de peregrinos de Senlis (Francia), comenzado en 1680, se incluye una canción titulada Chanson nouvelle sur tous les passages et lieux remarquables qu'il y a aux chemins de Saint-Jacques, SaintSalvateur et Mont-Sarra (o, simplemente, Chanson nouvelle). Describe, como anticipa su título, el recorrido desde esta localidad situada al norte de París, hasta Santiago de Compostela. En el mismo se incluye el paso por Asturias y, por lo tanto, por Oviedo y su catedral de San Salvador. El trayecto de regreso a Francia no es una repetición exacta del de ida, pues se presenta también como una peregrinación al monasterio de Montserrat. Después de atravesar Galicia, León y Castilla, las tierras riojanas aparecen como el inicio de un desvío con respecto al Camino Francés, que ha de llevar hasta Cataluña y que se podría identificar, al menos en buena medida, con la ruta jacobea del Ebro recorrida en sentido inverso:

\author{
Ceux qui par dévotion \\ S'en yront \\ Pour faire ce beau voyage \\ A Mont Sarra [Montserrat], visiter \\ Et prier \\ La Sainte Vierge l'image. \\ Pour commancer le chemin \\ Plus certain \\ A Saint-Dominique faut prendre, \\ Passer de là à Grenoble \\ Ou Carolle [Calahorra] \\ Pour à Tudelle [Tudela] se rendre. \\ (Müller, 1914: 210. vv. 235-246)
}

- Incluyen lugares donde existían hospitales destinados a acoger peregrinos, como, por ejemplo, Burdeos o el túnel de san Adrián ${ }^{38}$.

- Mencionan santuarios de visita obligada durante la peregrinación. Siempre suelen hablar de dos lugares de especial importancia. Uno es la mencionada catedral de San Salvador de Oviedo, famosa por sus importantes reliquias ${ }^{39}$. El otro es Santo Domingo de la Calzada. El paso por esta ciudad no era necesario para los peregrinos franceses que entraban en España por Irún (cada vez más numerosos desde finales de la Edad Media), ya que éstos se incorporaban al Camino Francés

${ }^{37}$ La Complainte des Pelerins d'Aurillac, antes mencionada, es una excepción en este aspecto, pues no incluye alusión alguna a la localidad calceatense. Además, el recorrido que describe tiene como punto de partida Aurillac, ciudad francesa que no se ubica en el norte o en el oeste de Francia, pues está situada en el Macizo Central.

38 Vid. Vázquez de Parga, Lacarra y Uría Ríu (1949, vol. 2: 55 y 446-447).

39 Vid. Vázquez de Parga, Lacarra y Uría Ríu (1949, vol. 2: 479-492). 
en Burgos. Este trayecto Irún-Burgos es el que suelen reflejar las canciones de itinerario, en lugar del recorrido navarro desde Roncesvalles. Por lo tanto, acudir a Santo Domingo implicaba desviarse de dicho trayecto (Irún-Burgos). Por ello, el que estas composiciones recojan este desvío constituye una manifestación de que era algo que se hacía habitualmente ${ }^{40}$. En consecuencia, demuestra claramente el prestigio y la difusión del milagro del peregrino ahorcado y de las aves resucitadas, pues éste era el motivo por el cual los peregrinos franceses se desviaban. En la canción titulada La grande Chanson des Pèlerins qui vont à $S$. Jacques, se dice:

Arrivés à Saint-Dominique,

Le coq chanta;

Nous l'entendîmes dans l'église,

Nous étonna.

On nous dit que le pélérin,

Par un miracle,

A ce signe ressuscita,

Ce n'est pas une fable.

(Daranatz, 1927, vol. 2: 38, vv. 105-112)

- Informan sobre determinadas actuaciones, que podrían ser calificadas como trámites de obligado cumplimiento para poder continuar el viaje. Una de ellas, por ejemplo, era el cambio de moneda, que solía efectuarse en Bayona, justo antes de entrar en España ${ }^{41}$.

- Advierten sobre lo duro o peligroso que era el paso por ciertos puntos del camino, como la zona del puerto de Pajares, entre León y Asturias o el puente conocido como Pont qui tremble $e^{42}$.

- Recogen sucesos y anécdotas diversos, como el difícil trance en el que se ven envueltos los peregrinos al llegar a Ribadeo. Allí están a punto de ser llevados a las galeras, probablemente porque son confundidos con vagabundos o delincuentes ${ }^{43}$.

En segundo lugar, hay un grupo de canciones de naturaleza narrativa, en las cuales se relatan los milagros obrados por el apóstol Santiago, por Dios, por la Virgen o, incluso, por algún otro santo, en las personas de romeros jacobeos que han sufrido alguna clase de contrariedad grave durante su viaje. Aquí hay que contemplar una serie de canciones que cuentan el mencionado milagro del peregrino ahorcado y de las aves resucitadas ${ }^{44}$. Lo más sorprendente para nosotros puede ser el hecho de que algunas de ellas proceden de Canadá. Esto no hace sino confirmar el hecho, antes comentado, de la fama internacional de este milagro calceatense. Una de estas canciones, titulada Les trois pèlerins de SaintJacques, relata así el prodigio:

\footnotetext{
40 Vid. Vázquez de Parga, Lacarra y Uría Ríu (1949, vol. 2: 32-33).

41 Vid. Vázquez de Parga, Lacarra y Uría Ríu (1949, vol. 2: 439).

42 Vid. Vázquez de Parga, Lacarra y Uría Ríu (1949, vol. 2: 564-565).

4. Vid. al respecto Vázquez de Parga, Lacarra y Uría Ríu (1949, vol. 2: 569-570).

44 Vid. al respecto Smith (1873: 471-476). Barbeau (1962: 265-268) y Roy (1997: 416-417).
} 
Ils ont foullé les trois. Le jeune avait la tasse.

- Adieu, père, adieu, mère! Ah! je m'en vas en voyage!

Mais quand vous reviendrez, passez voir la potence.

Ils ont bien été six mois, six mois dans leur voyage.

Tant loin qu'il voit venir. - Voilà mon père, ma mère!

- Monsieur le prévost, voilà mon fils qui parle!

- Mais c'est aussi bien vrai qu'on vole un coq qui chante.

Le coq se rempluma, par trois fois il chante.

Ont dépendu le garçon, ils ont pendu la servante.

Eh! là, grand Dieu! vous jugez l'innocence.

(Barbeau, 1962: 265, vv. 12-21)

Otro género en el que la presencia de La Rioja jacobea goza de una presencia estimable es el que, en su conjunto, se podría denominar relatos e itinerarios franceses de viajes y de peregrinación. Aquí se incluirían los testimonios escritos de distintos viajeros del país vecino (con o sin motivación piadosa), tanto en forma de relato en prosa como de trayectos en los que se muestran las etapas realizadas y la distancia entre unas y otras, con algunas explicaciones más o menos extensas sobre las mismas.

A comienzos del siglo Xv, en 1417, el gascón llamado Nompar de Caumont peregrinó a Compostela y, como reflejo escrito de este viaje, dejó su Voiatge à $S^{\prime}$ Jacques de Compostelle. Este texto es básicamente un itinerario que, en lo que respecta a su trazado español, comienza en Roncesvalles. Por lo tanto, Caumont atravesó toda la actual provincia de Navarra (menciona Pamplona, Puente la Reina, Estella y Los Arcos) y, a continuación, la de La Rioja. De esta tierra nombra las localidades de Logroño, Navarrete, Nájera y Santo Domingo de la Calzada. De Nájera hace el siguiente comentario histórico, en relación con la batalla que tuvo lugar en 1367 entre Enrique de Trastámara y Pedro I el Cruel:

Et davant ceste place, ha un grant champ moult lonc et ample où le Prince de Gales, duc de Guienne, fils du bon roy Edoart, qui avoit en sa compaiginie de moult belle chevallerie et escuierie de Guascons, et d'autres d'Angleterre, gueagne le bataille et esconffit le roy Enric; et mist en possession le roy Pedro de tout le royaume d'Espaigne, comme roy droyturier. (Seigneur de Caumont, 1975: 143)

En lo que concierne a Santo Domingo, no deja de hacerse eco de su milagro. El relato que presenta es el más antiguo de cuantos reproducen dicha historia en su totalidad ${ }^{45}$.

45 El documento más antiguo de naturaleza no literaria en el que se hace algún tipo de alusión al milagro del gallo y la gallina es una bula promulgada en 1350 por el papa Clemente VI. En el Archivo Catedral de Santo Domingo de la Calzada se conserva el traslado (fechado en 1440) de dicha bula, wen la que se conceden diversas indulgencias a lo que visitan la Catedral y contribuyen al sostenimiento de la fábrica, entre ellos a los que contemplen el gallo y la gallina y otras reliquias allí existentes. Según esto, habria que datar la documentación del milagro a comienzos del s. xiv o tal vez a finales del s. xIII». (Sáenz Terreros, 1986: 60). En este traslado puede leerse lo siguiente: "Tunc precipue benigno fauore prosequitur cum deuota ipsorum humilitas sanctorum meritis et precibus adiuuatur. Cupientes igitur vt ecclesia cathedralis Sancti Domini calceatensis et alie reliquie que ibi continentur congruis honoribus frequentetur et a Christi fidelibus iugiter venerentur [... ]. Et omnes videntes gallum et gallinam ibidem existentes et alias reliquias in predicta ecclesia adorauerit et deuoten (Lopez de Sila- 
Cuenta básicamente lo mismo que el que se recoge en la Histoire de la vie, prédication, martyre, translation et miracles de sainct laques le Majeur. De todas formas, la narración de Caumont termina de la siguiente manera:

Et le jutge avoit fait aprester son disner où il avoit en l'aste au feu ung coli et une geline qui rosti estoient. Et le jutge vayt dire qu'il creyroit ainxi tost que celle poulaille de l'aste que estoit près cuyte, chantessent, comme que celluy enfant fusse vif. Et encontinent le coli et le jaline sordirent de l'aste et chantérent. Et lors le jutge fut moult merveillés et assembla gens pour aler au gibet. Et trouvérent qu'il estoit veoir, et le mirent à bas sain et vif. Et il ala compter comme il ne savoit riens de le tace et comme le chambrier l'avoit prié. Et ycelle fust prise et comffessa le vérité, qu'elle l'avoit fait pour ce qu'il n'avoit voulu fere sa voulenté; et fut pendue. Et encore ha, en l'eglise, ung coli et une jéline de le nature de ceulx qui chantérent en l'aste davant le jutge; et je les ay veuz de vray, et sont toux blancs. (Seigneur de Caumont, 1975: 145)

A comienzos del siglo XVII, entre 1603 y 1604, Barthélemy Joly, consejero y capellán del rey, viajó a España acompañando al abad y general de la orden del Cister, el cual iba a visitar los monasterios pertenecientes a la $\mathrm{misma}^{46}$. La relación escrita que dejó de su estancia en este país no fue publicada hasta 1909 por L. Barrau-Dihigo, en el número 20 de la Revue Hispanique y con el título Voyage de Barthélemy Joly en Espagne (16031604). En realidad, Joly no pasó por La Rioja; sin embargo, al hablar de las distintas órdenes de caballería existentes en España, señala que, según dicen, la orden de Santiago se creó a iniciativa del rey Ramiro I, después de su victoria sobre los moros en la batalla de Clavijo (Joly la sitúa en Albelda):

En l'an 780 ou enurion, un roy d'Espagne, nomé Mauregato se trouua tellement pressé de guerre par les Mores qu'il fust contrainct leur accorder cinquante filles nobles et cinquante roturieres de tribut annuel, que l'on appella el pecho del bordel, continué à payer jusque au roy Ramiro en J'an 837, qui le refusa courageusement et sur ceste querelle vainquist les Mores en bataille en un lieu nomé Albelda, pres Logrogne, en la frontiere de Nauarre, où $S$. Jacques, patron d'Espagne, parust au fort de la meslee, aydant les Espagnolz, à cheual, l'espee au poing, toute rouge de sang ennemy et tel que les cheualiers de S. Jacques le portent aujourdhuy, ce disent-ilz. Ce roy Ramiro institua dès lors et donna quelque forme de commencement à cest ordre de cheualiers, à ce que l'on tient. (Joly, 1909: 131) ) $^{47}$

En 1659, François Bertaut, consejero en el Parlamento de Ruán y prior del Monte de los Enfermos, hubo de acompañar a España al mariscal De Grammont, cuando éste fue enviado con el encargo de pedir la mano de María Teresa de Austria para Luis XIV ${ }^{48}$. Tal matrimonio había sido acordado ese mismo año en la Paz de los Pirineos. Escribió Bertaut dos obras sobre España: Relation d' un voyage d'Espagne où est exactement décrit l'estat de la Cour de ce royaume et de son gouvernement (1664) y Journal du voyage d'Espagne (1669). No es, por lo tanto, un peregrino. Sin embargo, en su viaje tuvo que

nes y Sáinz Ripa, 1985: 161-162). Vid. también, en relación con esto y con el texto de Caumont, Vázquez de Parga, Lacarra y Uría Ríu (1949, vol. 1: 577-579), Sáenz Terreros (1986: 56 y 60), Pérez Escohotado (1999: 33-34) y Pérez Escohotado (2002: 40-42).

46 Vid. Bennassar y Bennassar (1998: 1222) y García Mercadal (1999, vol. 2: 687).

47 Vid. también García Mercadal (1999, vol. 2: 744).

48 Vid. Bennassar y Bennassar (1998: 1203) y García Mercadal (1999, vol. 3: 391). 
atravesar La Rioja y, al pasar por Santo Domingo de la Calzada, se hizo eco de su milagro. De éste deja constancia escrita en el Journal du voyage d'Espagne. Sobre el gallo y la gallina que se guardan en el interior de la iglesia, señala:

Et je fus encore plus étonné de voir dans l'église au-dessus d'un autel qui est à main gauche, une niche fermée d'une grille de fer, où étaient un coq et une poule blanche en vie, qui chantaient d'importance, et se promenaient là-dedans, où ils faisaient leurs œufs et toutes ordures: et ils mettraient à l'Inquisition un homme qui douterait de cette histoire, la plupart croyant que c'est le même coq et la même poule qui ressuscitèrent, et qui sont devenus immortels comme Élie et Hénoch. On ne laisse pas pourtant de leur donner à manger, et c'est une marque de dévotion aux pèlerins qui y passent; à qui aussi on donne quelquefois des plumes de ces bêtes, qu'ils mettent sur leurs chapeaux avec grand respect; ce qui fait encore un autre miracle, car ils disent que leurs plumes ne diminuent point. (Bennassar y Bennassar, 1998: 948) ${ }^{49}$

Poco antes, a su paso por Logroño, Bertaut hace también alusión a la batalla de Clavijo:

De l'autre côté de cette pegna est la montagne el monte del Clavijo, où il y a un vieux château; et ce fut où se donna la sangriente hatalla del Clavijo, en la qual el rey don Ramiro deroto a un numero infinito de Moros, e estando en el ayre Saint-lago, la sanglante bataille de Clavijo en laquelle le roi don Ramire mit en deroute un nombre infini de Mores, où saint Jacques paraissait en l'air, dont ce roi porte un image de bois; et pour cela on y a fondé depuis un couvent de l'ordre de Saint-Bernard, et la grande église a pour patron saint Jacques. (Bennassar y Bennassar, 1998: 698) ( $^{\text {so }}$

En el mencionado libro de la cofradía de peregrinos de Senlis se recogen también varios itinerarios de peregrinación a Santiago. Cada uno de ellos reproduce algún tramo de las rutas hacia Compostela, San Salvador de Oviedo, Montserrat o también el camino de retorno a Francia. Llama poderosamente la atención que buena parte de estos itinerarios (cinco de un total de once, vid. Müller, 1914: 185-191) presentan la localidad riojana de Santo Domingo de la Calzada como etapa inicial o final. Podría decirse que para los peregrinos de esta cofradía, que sin duda eran quienes se servían de estos recorridos como guías a lo largo de su viaje, esta población era un punto de referencia importante, probablemente a causa del gran prestigio de su conocido milagro.

Uno de dichos trayectos presenta las etapas que componen el tramo comprendido entre Irún y Santo Domingo de la Calzada. En otro se reproduce el trayecto desde esta última localidad hasta Santiago (pasando por Burgos, León y Galicia) ${ }^{51}$. Hay un último itinerario que se inicia en Burdeos, pasa por Roncesvalles y termina en Santo Domingo de la Calzada. Los tres recorridos incluyen menciones de varias localidades riojanas: Logroño, Navarrete, Nájera, Santo Domingo de la Calzada, Grañón, Haro y Zarratón ${ }^{52}$. De la localidad calceatense hace el siguiente comentario, relativo también a su milagro:

\footnotetext{
49 Vid. también García Mercadal (1999, vol. 3: 398-399).

so Vid. también García Mercadal (1999, vol. 3: 398).

\$1 El libro de la cofradía de peregrinos de Senlis presenta, después de este itinerario, otro comprendido igualmente entre Santo Domingo y Santiago, que incluye el paso por León (y previamente por Burgos, como es obvio, aunque esta ciudad no es mencionada) y Oviedo (vid. Müller, 1914: 188-190).

52 Vid. Müller (1914: 185-186 y 197). Sobre la presencia de Haro y Zarratón en estos itinerarios, vid. Vázquez de Parga, Lacarra y Uría Ríu (1949, vol. 2: 453-454).
} 
Cette ville est celle où fut fait le miracle du pèlerin que saint Jacques conserva 36 jours au gibet où il avoit esté pendu innocemment; là on y voit la grande esglise, le coq et la poule, en mémoire de ce miracle, qui sont dans une grille de fer à gauche en entrant. (Müller, 1914: 186)

Este libro recoge también el recorrido comprendido entre (nuevamente) Santo Domingo de la Calzada y la localidad francesa de Toulouse. Se trata de un camino de peregrinación y, al mismo tiempo, de regreso a Francia ${ }^{53}$. Los dos santuarios españoles más importantes del mismo son la basílica de Nuestra Señora del Pilar, en Zaragoza, y el monasterio de Montserrat. Las etapas iniciales de esta ruta son, evidentemente, poblaciones riojanas:

Sy le pellerin veut faire le voyage de Nostre-Dame de Mont-Sarrat, il peut prendre le chemin qui s'ensuit:

De Saint-Dominique à Grenoble [Grânon]

Navarin [Najera]

3 l. [leguas]

Caroles [Calahorra]

31.

La faire [Alfare]

31.

(Müller, 1914: 191)

31.

Como puede verse, este tramo riojano es básicamente el mismo que aparece descrito en la Chanson nouvelle. Se incluye de nuevo el topónimo Grenoble, que, al igual que en esta canción (1914: 210, n. 1), Müller identifica como Grañón. En ambos textos se da la circunstancia de que Grenoble está situada al este de Santo Domingo de la Calzada. Esto es indudablemente un error, si se acepta la identificación propuesta por Müller, pues Grañón está en realidad al oeste de la localidad calceatense. Si se hace una comparación entre los distintos itinerarios del libro de la confradía de Senlis y los recorridos descritos en la Chanson nouvelle, se comprueba que casi todas las localidades contenidas en ésta se encuentran igualmente en aquéllos. Se da además el hecho de que en los unos y en la otra hay varias series de poblaciones y lugares consecutivos entre las que hay una enorme semejanza. Así puede comprobarse en el curso de la ruta comprendida entre Zaragoza y Montserrat ${ }^{54}$ :

$\begin{array}{llc}\text { Fines } & 21 . & \text { De Fines, Caspes, Mesle, Bestiers } \\ \text { Caspe } & 41 . & \text { A Daugiers, } \\ \text { Mesle } & 41 & \text { More d'ebrone, Falcrette, } \\ \text { Béthière } & 41 . & \text { Ride chaude et Mon Barron, } \\ \text { Daugière } & 41 . & \text { Nous passons }\end{array}$

${ }_{53}$ Este trayecto va seguido de un periplo de Toulouse a Senlis (vid. Müller, 1914: 193-196).

$\$ 4$ Los topónimos originales que aquí se proponen como equivalentes, seguros o probables, de los nombres en francés comunes al itinerario y a la estrofa son, por orden de exposición, los siguientes: Fuentes de Ebro (o quizá, también, Pina de Ebro) [Fines], Caspe, Maella [Mesle]. Batea [Béthière o Bestiers], Gandesa [Daugière o Daugiers], Mòra d'Ebre [More de Bronc o More d' ebrone], Falset, Riudecois (o quizá, también, Riudecanyes) [Ridechaude o Ride chaude], Montbriò del Camp [Mont baron o Mon Barron], Tarragona, EI Vendrell [Villers o Villerette], Villafranca del Penedés [Ville franc o Villefranche], La Granada [La Grenade], Piérola (o quizá, también, Piera) [Pillerole o Pillerolle], Collbató [Callebot o Callebotte] y Montserrat [Mont Sarat o Mont Sarra]. El único topónimo no compartido por ambos textos es Falcrette, presente solamente en la canción. Se corresponde, seguramente, con Falset. Vid. Iñarrea las Heras (1998-2000: 142, n. 44). 


\begin{tabular}{|c|c|c|}
\hline $\begin{array}{c}\text { More de Bronc } \\
{[\ldots]}\end{array}$ & 31. & A Taragone et Villerette \\
\hline Ridechaude & 21. & A Villefranche et La Grenade \\
\hline Mont baron & 21. & Au plus tard \\
\hline $\begin{array}{c}{[\ldots]} \\
\text { Tarragone }[\ldots]\end{array}$ & 11. & $\begin{array}{l}\text { A Pillerolle passames, } \\
\text { Puis de la a Callebotte, }\end{array}$ \\
\hline Villers & 21. & Une crotte, \\
\hline Ville franc & 21. & De Mont Sarra Ia montagne. \\
\hline La Grenade & 21. & (Müller, 1914: 210, vv. 253-264) \\
\hline Pillerole & 21. & \\
\hline Callebot $[\ldots]$ & 31. & \\
\hline $\begin{array}{l}\text { Mont Sarat } \\
\text { (Müller, 1914: 1s }\end{array}$ & $\begin{array}{l}31 . \\
2)\end{array}$ & \\
\hline
\end{tabular}

Por lo tanto, podría afirmarse, como algo muy probable, que el anónimo autor de la Chanson nouvelle utilizó los itinerarios del libro de la cofradía de peregrinos de Senlis en su labor de composición. Debió de hacer una selección de localidades, ya que este canto no es tan detallado y minucioso como los itinerarios, aunque mantuvo fielmente el orden de sucesión de las mismas ${ }^{35}$. Precisamente por ello, colocó también Grenoble a continuación de Santo Domingo de la Calzada (dentro del camino que conduce a Zaragoza, Monserrat y Toulouse). El hecho de que justo después aparezca Calahorra, junto con una cierta (y pequeña) semejanza fonética, puede llevar a creer que Grenoble es en realidad Logroño. Sin embargo, esta última ciudad se encuentra en el itinerario comprendido entre Burdeos y Santo Domingo de la Calzada (por Roncesvalles), y aparece transcrita como Logrogno. Por otro lado, es importante tener en cuenta que, como se ha visto, el canto reproduce, como parte del camino de Irún a Burgos, el desvío hasta Santo Domingo de la Calzada y la posterior continuación hasta la ciudad castellana. En ella se incluye Grañón (Grenon), que aparece correctamente situada. Los itinerarios de Irún a Santo Domingo y de Santo Domingo a Compostela (por Burgos, León y Galicia) contienen entre ambos casi las mismas poblaciones riojanas que la canción (ésta no incluye Farat [Zarratón]). Entre ellas está Grañón, bien colocada y transcrita en francés como Gregnon. Tanto esta forma como Grenon son, sin duda, mucho más parecidas a la original en castellano que Grenoble. Si realmente el creador de la Chanson nouvelle copió de los trayectos los nombres de las poblaciones incluidas en ella, lo hizo sin duda con gran fidelidad. Por ello, cabe concluir que el poeta no escogió para su obra la capital riojana (del mismo modo que tampoco eligió tantas otras localidades); que Grenoble es ciertamente Grañón, pues no se concibe que pudiera llegar a deformar Logrogno hasta el punto de transformarlo en Grenoble ${ }^{56}$, mientras que sabe copiar bien los demás topónimos (parece claro que el autor de los itinerarios tradujo Grañón como Grenoble influido por una cierta analogía fonética entre la población riojana y la ciudad francesa capital del depar-

55 La única alteración que el poeta ha introducido en el orden de sucesión de las localidades incluidas en su obra es la colocación de la abadía del Grand Cavalier, nombre dado por los peregrinos franceses al hospital del monasterio de Santa María de las Tiendas (vid. Vázquez de Parga, Lacarra y Uría Ríu, 1949, vol. 1: 218), antes de Carrión de los Condes, cuando en realidad está ubicado después de esta localidad, más cerca ya de Sahagún.

56 Por lo tanto, Ja apreciación de lñarrea Las Heras (1998-2000: 140), según la cual Grenoble es probablemente Logroño, no puede ser considerada como correcta. 
tamento de Isère ${ }^{57}$ ); que la posición de Grenoble en el trayecto entre Santo Domingo de la Calzada y Toulouse es producto de un error cometido por quien lo puso por escrito y que este error fue repetido por el autor de la canción. Se adivina en éste un proceder más bien mecánico en su forma de copiar, ya que dicha equivocación no se da en las estrofas que reproducen el tramo riojano del Camino Francés.

No hay que pasar por alto la presencia, en el tramo riojano citado anteriormente, del topónimo Navarin, justo después de Grenoble. Müller considera que hace referencia a Nájera. Sin embargo, si se examina el itinerario entre Burdeos y Santo Domingo de la Calzada por Roncesvalles, se aprecia que en él se encuentran las localidades de Navarret (Müller la identifica como Navarote: obviamente, se trata de Navarrete) y de Nagera (Nájera). Las claras semejanzas ortográficas y fonéticas entre Navarin y Navarrete aconsejan corregir la apreciación de Müller y concluir que estos dos nombres corresponden a la misma población riojana.

Ya en el siglo XVIII, aparecen los testimonios de tres peregrinos jacobeos franceses que pasaron por La Rioja. El primero de ellos fue Guillaume Manier, sastre del norte de Francia (concretamente de Carlepont, en Picardía), que, aun habiendo entrado en España siguiendo el trayecto entre Irún y Burgos, se desvió a Santo Domingo. Esto sucede, según su obra titulada Voyage d'Espangne (1736), en octubre de 1726. También él presenta el relato del milagro, aunque con cierta peculiaridad, no recogida en los otros textos citados, relativa al juez incrédulo:

Et pour punition du juge, il y eut un jugement rendu contre lui et ses successeurs, qu'ils porteraient au col une corde pour ressouvenir de ce jugement. Ce qui s'est pratiqué longtemps, et depuis la chose s'est adoucie: ils portent un ruban rouge et donnent à souper tous les jours à un pèlerin, en reconnaissance. (Manier, 1890: 55) ${ }^{58}$

Años más tarde, entre 1748 y 1749, Jean Bonnecaze natural del pueblo bearnés de Pardies, lleva a cabo la peregrinación a Compostela. El relato que deja de la misma es bastante breve y forma parte de una autobiografía redactada en 1777 y titulada Testament politique du sieur Jean Bonnecaze, de Pardies, prêtre chapelain aux forges d'Asson, appartenant à M. d'Angosse, marquis de Louvie ${ }^{59}$. Sin embargo, no deja de hacer una pequeña alusión a su paso por Logroño, en el trayecto de regreso. En esta localidad, una mujer, apiadada al verle caminar descalzo, le dejó un par de zapatos con los que pudo llegar hasta su casa:

Nous fîmes douze lieues de chemin le premier jour. Nous étions à sept heures du matin à Navarrenx. C'est dans cette ville que j'achetai un chapeau pour trente sols et vendis mon béret pour douze sols: je n'avais qu'une mauvaise paire de souliers qui ne me servirent que jusqu'à

${ }^{37}$ En este sentido, puede ser revelador el itinerario inglés de peregrinación escrito en verso hacia finales del siglo xIv y publicado por Samuel Purchas en 1625. En él se menciona, tras el paso por Santo Domingo de la Calzada, la localidad de Grunneole, que bien podría ser Grañón (vid. Vázquez de Parga, lacarra y Uría Ríu, 1949. vol. 1: 216 y vol. 3: 123-124). Las deformaciones de los topónimos cspañoles en relatos e itinerarios de peregrinación escritos en otros idiomas es algo muy habitual.

s8 Vid. también Bennassar y Bennassar (1998: 948-950) y García Mercadal (1999, vol. 4: 727-728).

59 Vid. al respecto Bennassar y Bennassar (1998: 1206), Bonnecaze y Racq (1998: 9) y Manier, Bonnecaze y Nompar de caumont (2001: 182-186). 
Pampelune. Depuis lors, je marchai pieds-nus par tout le chemin jusqu'à mon retour à Logroño, ville de Castille, où une veuve, touchée de compassion, m'en donna une paire qui me servirent pourr arriver chez mon père. Je fis au moins cent-quatre-vingts lieues, pieds-nus. (Manier, Bonnecaze y Nompar de Caumont, 2001: 188) (6) $^{6}$

En 1790, Jean-Pierre Racq, nacido en Bruges (Francia, no Bélgica), hizo igualmente su viaje a Santiago. Elaboró un itinerario de naturaleza muy similar al de Caumont, constituido por los trayectos de ida y de vuelta. Menciona, a su paso por La Rioja, Logroño, Navarrete, Nájera, y Santo Domingo de la Calzada. De esta última hace estos dos parcos pero significativos comentarios:

Vous verrez le coq et la galine.

Charité a thopital.

(Vázquez de Parga, Lacarra y Uría Ríu, 1949, vol. 3: 141) (1) $^{6}$

La misma brevedad de la alusión al milagro permite suponer que era un relato muy conocido, al menos para los peregrinos jacobeos.

Como conclusión a todo lo expuesto se podría decir que la presencia de La Rioja jacobea en las producciones mencionadas presenta dos peculiaridades. Por un lado, nunca es excesivamente extensa en la mayor parte de estas obras. Incluso, la acción de los dos textos dramáticos no se desarrolla en Santo Domingo de la Calzada. El peso de la influencia riojana en ambas obras es no es apreciable de manera evidente. Bien es cierto, de todos modos, que el milagro del ahorcado es el contenido esencial de las canciones de peregrinación narrativas que aquí se han tenido en cuenta (aunque ninguna de ellas es muy larga). Por otro lado, sin embargo, el número de las creaciones contempladas en el presente trabajo es, como se ha visto, considerable, al igual que la cantidad de géneros literarios en los que se reparten. Esto viene a ser una demostración, establecida desde la óptica proporcionada por el estudio de la literatura y la música francesas y francófonas, de la importancia de La Rioja en la ruta jacobea. Pero es también una confirmación de su condición fundamental de etapa, junto con otras muchas, dentro de un largo camino cuya culminación (Compostela) queda aún muy lejos. Con todo, no deja de constituir un tema de estudio literario digno de atención y de una valoración positiva.

\section{BIBLIOGRAFÍA}

ANÓNImO (1603): con Histoire de la vie, prédication, martyre, translation et miracles de sainct laques le Majeur, Ruán, Loys Costé.

ANÓNImo (1718): Les Chansons des pélerins de S. Jacques, Troyes.

ANONIMO [1850]: Cantique, (goigs) en l' honneur de Saint-Jacques le Majeur, Perpiñán, Antoine Fourquet.

on Vid. también Bennassar y Bennassar (1998: 43-44) y Bonnecaze y Racq (1998: 23).

61 Vid. también Bonnecaze y Racq (1998: 36). 
Anónimo (1858): Ludus sancti Jacobi. Fragment de mystere provençal, Camille Amaud (ed.), Marsella, Imprimerie d'Arnaud.

ANÓNimo [1862]: La Grande Chanson des pèlerins faisant le voyage de Saint-Jacques et de Rome, Carcasona, Impr. P. Polère.

Anónimo (1913): L'Entrée d'Espagne, 2 vols., Antoine Thomas (ed.), París, Firmin Didot.

ANónImo (1944): Liber Sancti Jacobi. Codex Calixtinus, Walter Muir Whitehill (ed.), Santiago de Compostela, Seminario de Estudios Gallegos.

Anónimo (1951): Liber Sancti Jacobi. Codex Calixtinus, traducción de A. Moralejo, C. Torres, J. Feo, reedición preparada por X. Carro Otero, [Santiago de Compostela], Xunta de Galicia, 1998.

ANÓNIMO (1966): Les anciens poètes de la France: Gui de Bourgogone. Otinel. Floovant, F. Guessard y H. Michelant (eds.), Nendeln, Liechtenstein, reimpresión de la edición de París, 1859.

Aurenche, H. (1948): Chemins de Compostelle, París, Bonne Presse.

BarbeaU, Marius (1962): Le Rossignol y Chante, Ottawa, Ministère du Nord Canadien et des Ressources Nationales, Musée National du Canada.

BEAUfRËE, Abel (1978): Aurillac et la Haute-Auvergne sur les chemins de Compostelle, París, Centre d'Études Compostellanes.

BÉDIER, Joseph (1966): Les légendes épiques. Recherches sur la formation des chansons de geste, 4 vols., París, Champion.

Bennassar, Bartolomé y Bennassar, Lucille (1998): Le Voyage en Espagne. Anthologie des voyageurs français et francophones $d u X V I^{*}$ au XIX' siècle, París, Robert Laffont.

BONNECAZE, Jean y RACQ, Jean-Pierre (1998): Voyage de deux pèlerins à Compostelle au XVIII siècle, Toulouse, CAIRN.

CANTELOUBE, Joseph (1951): Anthologie des chants populaires français, groupés et présentés par Pays ou Provinces, 4 vols., París, Durand.

Caumont, Seigneur de (1975): Voiatge à $S^{\prime}$ Jaques de Compostelle et à Nostre Dame de Finibus Terre, en Voyaige d' Oultremer en Jhérusalem, marqués de La Grange (ed.), Ginebra, Slatkine Reprints, 141-150, reimpresión de la edición de París, 1858.

Daranatz, J.-B. (1927): Curiosités du Pays Basque, 2 vols., Bayona, Librairie Lasserre.

DAUX Camille (1899): Les Chansons des pèlerins de Saint-Jacques, Montauban, Édouard Forestié.

DEсомвE, Lucien (1884): Chansons populaires recueillies dans le département d'Ille-et-Vilaine, Rennes, $\mathrm{H}$. Caillière.

Echevarria Bravo, Pedro (1967): Cancionero de los peregrinos de Santiago, Madrid, Centro de Estudios Jacobeos.

Filgueira VAlverde, José (1970): Historias de Compostela, Santiago de Compostela, Edicións Xerais de Galicia.

Filgueira VAlVERDE, José (1985): «La littérature sur le chemin du pèlerinage de Saint-Jacques de Compostelle. Poésie et thêatre», en Santiago de Compostela. 1000 ans de pèlerinage européen, Gante, Crédit Communal, 183-194.

FuCELll, Antonietta (1987): L'Itinerario di Bartolomeo Fontana, Perugia, Università degli Studi di Perugia, Edizioni Scientifiche Italiane.

García Mercadal, José (1999): Viajes de extranjeros por España y Portugal. Desde los tiempos más remotos hasta comienzos del siglo XX, 6 vols., [Valladolid], Junta de Castilla y León, Consejería de Educación y Cultura.

Gautier DE COINCI (1961-1966): Les Miracles de Nostre Dame, 4 vols., V. Frederic Koenig (ed.), Ginebra, Droz.

GIL DEL Río, Alfredo (1984): Roldán y el gigante Ferragut. Fantasía e Historia Medieval, Madrid, Algar, S. A. 
GIL DEL Rio, Alfredo (1999): El Camino Francés a Compostela. Evocaciones y leyendas siguiendo las estrellas, Madrid, Egartorre.

GolCoECHEA ARRONDO, Eusebio (1971): Rutas jacobeas, Estella, Los Amigos del Camino de Santiago.

HenraRD, Nadine (1998): Le Théatre religieux médiéval en langue d'oc, Ginebra, Droz.

HeUR, Jean-Maie d' (1967): «Saint-Jacques-de-Compostelle et saint-Jacques le Majeur dans la littérature occitane», Annales du Midi, 79, 3, 255-256.

IÑARREA LAS HERAS, Ignacio (1998-2000): «La presencia de otras vías de peregrinación en los cantos de itinerario franceses de la ruta jacobea: San Salvador de Oviedo y Montserrat», Anales de Filología Francesa, 9, 131-147.

Jehan Bagnyon (1992): L'Histoire de Charlemagne (parfois dite Roman de Fierabras), Hans-Erich Keller (ed.), Ginebra, Droz.

JEhAN DE SAINT-Quentin (1978): Dits en quatrains d'alexandrins monorimes de Jean de SaintQuentin, B. Munk Olsen (ed.), París, Société des Anciens Textes Français.

Joly, Barthélemy (1909): Voyage de Barthélemy Joly en Espagne (1603-1604), L. Barrau-Dihigo (ed.), extracto de la Revue Hispanique, XX.

KRIEG, E. (1886): Vieux chants et poésies des $X V^{m e}, X V I^{m e}, X V I I^{m e}$ et $X V I I I^{m e}$ siècles, París, Chez l'Auteur.

LEvvy, Émile (1882): «Le troubadour Paulet de Marseille», Revue des Langues Romanes, 3. ${ }^{a}$ serie, 7, 21, 261-289. Bibliothéque nationale de France/Gallica.

López de Silanes, Ciriaco y SáInz RIPA, Eliseo (1985): Colección Diplomática Calceatense. Archivo Catedral (Años 1125-1397), Logroño, Comunicad Autónoma de La Rioja, Instituto de Estudios Riojanos.

MANDACH, André de (1987): La Geste de Fierabras. Le jeu du réel et de l'invraisemblable, Ginebra, Droz.

MANIER, Guillaume (1890): Pèlerinage d' un paysan picard à $S^{t}$ Jacques de Compostelle au commencement du XVIII siècle, barón de Bonnault d'Houët (ed.), Montdidier, Abel Radenez.

MANIER, Guillaume (2002a): Pèlerinage d'un paysan picard à $S^{\prime}$ Jacques de Compostelle au commencement du XVIII siècle, barón de Bonnault d'Houët (ed.), presentación y cartografía de Joëlle Désiré-Marchand, Woignarue, Éditions La Vague verte, reimpresión de la edición de 1890.

MANIER, Guillaume (2002b): Un paysan picard à Saint-Jacques-de-Compostelle (1726-1727), Jean-Claude Bourlès (ed.), París, Payot \& Rivages.

MANiER, Guillaume; Bonnecaze, Jean y NomPar DE CAUmont (2001): Sur le chemin de Compostelle. Trois récits de pèlerins partis vers Saint-Jacques, París, Cosmopole.

MenaCA, Marie de (1987): Histoire de Saint Jacques et de ses miracles au Moyen-Age (VIIlèmeXIlème siècles), Nantes, Université de Nantes.

Morales Oliver, L. y LaPlane, G. (1950): «Rayonnement littéraire du thème de Saint Jacques en Espagne et en France», Bulletin de l'Institut Français en Espagne, 46, 224-226.

Mưller, E. (1914): «Une confrérie de Saint-Jacques à Senlis», Bulletin de la Société Historique de Compiègne, 16, 161-222.

NELLI, René (1980): «Trois poèmes autour d'un pèlerinage», en Le pèlerinage. Cahiers de Fanjeaux, 15, Toulouse, Édouard Privat, 79-94.

Nicolás de Verona (1864): La Prise de Pampelune, en Altfranzösische Gedichte aus venezianischen Handschriften, 2 tomos en un volumen, Adolf Mussafia (ed.), Viena, C. Gerold's Sohn.

OuY, Gilbert (1984): «Le Miracle des trois pelerins de Saint Jacques: Une pièce de théâtre médiévale sauvée de la destruction», Pluteus, II, 93-139.

PAssini, Jean (1984): Villes médiévales du chemin de Saint-Jacques-de-Compostelle (de Pampelune à Burgos). Villes de fondation et villes d'origine romaine, París, Éditions Recherche sur les Civilisations. 
PÉrez Escohotado, Javier (1999): De milagros y fronteras. El milagro del gallo y la gallina interpretado al fin razonablemente, [Logroño, Gobierno de La Rioja], Consejería de Educación, Cultura, Juventud y Deportes.

PÉRez EsCohơtado, Javier (coord.) (2002): Literatura y milagro en Santo Domingo de la Calzada, Logroño, Gobierno de La Rioja, Instituto de Estudios Riojanos.

PÉRICARD-MÉA, Denise (2000): Compostelle et cultes de saint Jacques au Moyen Âge, París, Presses Universitaires de France.

Real Ramos, Elena (1991): «El Camino de Santiago y la epopeya francesa», Queste, 6, 19-29.

RIQUER, Martín de (1992): Los trovadores: historia literaria y textos, 3 vols., Barcelona, Ariel.

RiQueR, Martín de y RiQuer, Isabel de (2002): La poesía de los trovadores, Madrid, Espasa Calpe.

Roy, Claude (1997): Trésor de la poésie populaire française, Textes choisis avec la collaboration de Claire Vervin, París, Plon.

Sáenz Terreros, M. ${ }^{a}$ V. ${ }^{a}$ (1986): El hospital de peregrinos y la cofradía de Santo Domingo de la Calzada, desde su fundación hasta la crisis del Antiguo Régimen, Logroño, Gobierno de La Rioja, Instituto de Estudios Riojanos.

SANTIAGo de LA VORAGine (1982): La Leyenda dorada, 2 vols., Madrid, Alianza.

SMITH, Victor (1873): «Chants de pauvres en Forez et en Velay», Romania, 2, 455-476.

Tobías Tobías Lidia, Ochoa Alfaro, Ángel José y Ochoa Moneva, Julio César (1999): Calahorra: en ruta hacia Santiago, Logroño, Gobierno de La Rioja, Instituto de Estudios Riojanos.

VÁzQUez de PARGa, Luis, LACARRA, José M." y URIA Rfu, Juan (1949): Las peregrinaciones a Santiago de Compostela, 3 vols., Madrid, Consejo Superior de Investigaciones Científicas.

VINCENT DE Beauvais (1990): Libellus Miraculorum S. Jacobi Apostoli, en Patrologiae Latinae Cursus Completus, J. P. Migne (ed.), vol. 163: 1369-1376. 